Revista Arbitrada Interdisciplinaria KOINONIA

Año V. Vol V. №10. Julio - Diciembre 2020

Hecho el depósito de Ley: FA2016000010

ISSN: 2542-3088

FUNDACIÓN KOINONIA (F.K). Santa Ana de Coro. Venezuela.

Lourdes Patricia Illescas-Guillén; Cecilia Ivonne Narváez-Zurita; Juan Carlos Erazo-Álvarez

http://dx.doi.org/10.35381/r.k.v5i10.690

\title{
Procesos de convergencia a Normas Internacionales de Contabilidad del Sector Público
}

\section{Convergence processes to International Public Sector Accounting Standards}

\author{
Lourdes Patricia Illescas-Guillén \\ lourdes.illescas@psg.ucacue.edu.ec \\ Universidad Católica de Cuenca, Cuenca \\ Ecuador \\ https://orcid.org/0000-0002-7934-6957 \\ Cecilia Ivonne Narváez-Zurita \\ inarvaez@ucacue.edu.ec \\ Universidad Católica de Cuenca, Cuenca \\ Ecuador \\ https://orcid.org/0000-0002-7437-9880 \\ Juan Carlos Erazo-Álvarez \\ jcerazo@ucacue.edu.ec \\ Universidad Católica de Cuenca, Cuenca \\ Ecuador \\ https://orcid.org/0000-0001-6480-2270
}

Recibido: 10 de marzo de 2020

Revisado: 25 de marzo de 2020

Aprobado: 29 de abril de 2020

Publicado: 19 de mayo de 2020

\section{RESUMEN}

En el presente artículo se diseñó un procedimiento metodológico para implementar las Normas Internacionales de Contabilidad del Sector Público (NICSP) en entidades del sector público no financiero de manera óptima. Al ser esta investigación no experimental, se manejó un enfoque cualitativo, mediante la revisión documental y aplicación de entrevistas semiestructuradas con un diseño transversal, puesto que la recolección de información el estado de su implantación tanto en Ecuador como en Perú. Los resultados determinaron la existencia de dificultades en esta fase de transición, siendo las más relevantes la falta de capacitación, directrices y herramientas por parte del ente rector. En consecuencia, se concluye en la importancia de contar con un proceso metodológico que direccione la ejecución de cada etapa y sirva de soporte a las entidades para solventar posibles eventos que amenacen la utilización de la nueva normativa en el sector público. 
Descriptores: Administración pública internacional; cooperación internacional; contabilidad de costes; recursos financieros. (Palabras tomadas del Tesauro UNESCO).

\begin{abstract}
In this article, a methodological procedure was designed to implement the International Public Sector Accounting Standards (IPSAS) in non-financial public sector entities in an optimal way. As this research is non-experimental, a qualitative approach was used, through the documentary review and application of semi-structured interviews with a cross-sectional design for the collection of information and the status of its implementation in both Ecuador and Peru. The results determined the existence of difficulties in this transition phase, the most relevant being: the lack of training, guidelines and tools provided by the governing body. Consequently, it attaches importance to a methodological process that directs the execution of each stage and supports the entities to solve possible events that threaten the use of the new regulations in the public sector.
\end{abstract}

Descriptors: International civil service; international cooperation; cost accounting; financial resources. (Words taken from the UNESCO Thesaurus).

\title{
INTRODUCCIÓN
}

El presente estudio refleja los diversos procesos llevados a cabo tanto en Ecuador como en Perú en su paso a las Normas Internacionales de Contabilidad para el Sector Público, los cuales van desde su origen y definición, la importancia de su implementación, aplicación contable, así como los inconvenientes y retos encontrados en su desarrollo, hechos que han marcado el camino hacia el progreso e innovación en el sector público. En Ecuador, el Ministerio de Economía y Finanzas, dentro del proceso de modernización permanente de su Sistema Nacional de Finanzas Públicas (SINFIP); y siempre pensando en mejorar las prácticas internacionales para su gestión, se encuentra en una transición a NICSP. En tal virtud, la Subsecretaría de Contabilidad Gubernamental ejecutó algunas actividades con el objetivo de conocer las experiencias de otros países para lo cual junto con el Banco Interamericano de Desarrollo (BID), asistieron a eventos contables; así también se efectuaron dos consultorías 
internacionales: la una permitió esclarecer las brechas entre la Normativa de Contabilidad Gubernamental y las NICSP, por otra parte, un segundo punto dedicado para la elaboración de un plan de convergencia a NICSP.

Además de las citadas actividades referentes a las NICSP, se realizaron otras tareas sistémicas para su implementación, como lo es el proyecto relacionado con un moderno instrumento para integrar la acción de las finanzas públicas, el cual fue contratado por el Ministerio de Economía y Finanzas, mediante la suscripción del acta de su constitución en el mes de diciembre del año 2016. La expectativa de este programa es la presentación de los primeros estados financieros consolidados del sector público bajo NICSP en el año 2020, y también, la publicación de la Normativa de Contabilidad Gubernamental, ya que se tomará en cuenta un formato para cada Norma Técnica de Contabilidad Gubernamental como una norma internacional, en el orden de: alcance, reconocimiento, medición inicial, medición posterior y revelaciones (Foro de Contadurías Gubernamentales de América Latina, 2019).

En lo que respecta al vecino país de Perú, la Dirección General de Contabilidad Pública, es la responsable en este proceso de transición, por lo que, de acuerdo con la normativa regulatoria peruana, y el estudio para la implementación de las Normas Internacionales de Contabilidad del Sector Público (NICSP), ha decidido acogerse a una aplicación indirecta. En tal razón, desde el año 2002, el Consejo Normativo de Contabilidad y la Dirección General de Contabilidad Pública, emitieron resoluciones para oficializar la instauración de las NICSP del IPSASB (Contraloría General de la República, 2017) de manera gradual, para lo cual, el ente rector los regula en sus diversos aspectos.

Estas regulaciones al ser de carácter obligatorio, por lo tanto, de aplicación para las entidades del sector público en la preparación de sus estados financieros, se asemeja con Ecuador en la utilización de la base contable de devengo como base de aplicación general; y también, las transacciones y otros eventos, priorizando lo particular y no la parte legal que pudiera influenciar (Foro de Contadurías Gubernamentales de América Latina, 2019). 
Además, estas entidades serán evaluadoras e implementadoras de las NICSP de forma progresiva, e informarán las brechas entre las políticas contables adoptadas y los requerimientos, tomando en consideración el aspecto costo- beneficio. Un punto mportante en el proceso de convergencia, es el uso de un Sistema de Devengo Modificado, con el riesgo de que algunos activos o pasivos no sean reconocidos. Por otro lado, la Dirección General de Contabilidad Pública aprueba y/o actualiza periódicamente el Plan Contable Gubernamental, por lo que ya cuentan con una versión actualizada al año 2019 (Foro de Contadurías Gubernamentales de América Latina, 2019).

De acuerdo a lo antes citado, por medio de este artículo se pretende conocer ¿Cuáles son los avances, dificultades y expectativas que han tenido Ecuador y Perú en su convergencia a NICSP?; de manera que, a partir de estos resultados se pretende diseñar un procedimiento metodológico para implementar las NICSP en entidades del sector público no financiero de manera óptima.

\section{Referencial teórico}

\section{Aspectos trascendentales dentro de la convergencia a NICSP}

La Federación Internacional de Contadores (IFAC), como organización representante de la profesión contable a nivel mundial, se encuentra constituido por más de 175 miembros, ubicados en alrededor de 130 países y jurisdicciones, contando con una representación aproximada de 3 millones de contadores. Como parte de su estructura se encuentra la Junta de Normas Internacionales de Contabilidad del Sector público (IPSASB por sus siglas en inglés) grupo responsable en la elaboración de las respectivas normas contables para el sector público, pilar fundamental para su implementación en los diferentes gobiernos del mundo (Velásquez \& Pérez, 2018) e (IFAC, 2019).

Por otro lado, (Ablan-Bortone, 2013), reseña que la nueva normativa es la encargada de definir los requisitos para identificar, estimar, exponer y explicar las operaciones y hechos en los estados financieros de manera general, cuya aplicación se rige para las 
entidades del sector público, tales COMI (F.K). Santa Ana de Coro. Venezuela. Lourdes Patricia Illescas-Guillén; Cecilia Ivonne Narváez-Zurita; Juan Carlos Erazo-Álvarez descentralizados sin fines de lucro. Por su parte, (Curiqueo-Ahumada, Estay- Mondaca \& Fernández-Rozas, 2017), así como las (Normas internacionales de contabilidad del sector público (NICSP), 2018), manifiestan que si bien el ámbito de aplicación de las NICSP es de carácter general para las entidades del sector público se exceptúan aquellas consideradas como empresas de negocios del Estado, las cuales deberían utilizar las NIIF-NIC.

Por otra parte, la (Organización Latinoamericana y del Caribe de Entidades Fiscalizadoras Superiores y la Comisión Técnica de Prácticas de Buena Gobernanza, 2015), definen a las NICSP como la integración de informes financieros de alta calidad de manera global.

En este contexto, (Bergmann \& Labaronne, 2013) señalan que existen 2 alternativas para implementar normas internacionales: el método directo con el uso de normativa contable internacional o el indirecto mediante el uso de normas nacionales, basadas en las normativas internacionales. En este caso el método indirecto es el más común; sin embargo, se corre el riesgo de omitir la adopción de normas con sus futuras consecuencias tanto en la implementación como en los resultados de los estados financieros entre países (Ortiz, Narváez \& Erazo, 2019).

Al respecto, (Ablan-Bortone, 2013), sostienen que la normativa posee

ciertas características, ya que el desarrollo de las NICSP de base devengo parten de una NIC/NIIF, con el objetivo de adaptarla a los requerimientos del sector público, por tal razón la relación vinculante entre las normas internacionales del sector privado y las ajustables al sector público. En consecuencia, el IPSASB estableció 32 normas internacionales aplicables al sector público, de las cuales 31 están relacionadas con la base del devengo y 1 norma se refiere a la base del efectivo; siendo la NICSP 2 relacionada al flujo del efectivo, por la naturaleza de la información, la que rompe este común denominador, (Curiqueo-Ahumada, Estay-Mondaca \& Fernández-Rozas, 2017). Por lo expuesto, las NICSP se constituyen en una normativa confiable y de calidad siendo éstas parte de las ventajas para su implementación lo cual contribuirá a la toma 
de decisiones y proporcionará transparencia en la rendición de cuentas. Por consiguiente, al considerarse las definiciones propuestas por (Curiqueo-Ahumada, Estay-Mondaca \& Fernández-Rozas, 2017), (IPSASB, 2019), el presente trabajo de investigación se orientará bajo estos preceptos, lo cual permitirá a los usuarios de la información contable pública conocer el estado en el que se encuentra actualmente el proceso de transición a NICSP, tanto en el caso de Ecuador como en el de Perú, y los resultados que se esperan conseguir de esta integración.

\section{Las NICSP adoptadas en Ecuador y Perú}

Al ser las NICSP normas que se aplican para entidades del sector público, es importante conocer su clasificación, siendo ésta de dos tipos: financiera y no financiera (Foro de Contadurías Gubernamentales de América Latina, 2019), las cuales a su vez se encuentran conformadas por varias instituciones, que serán descritas a continuación en figura 1 de acuerdo al presente estudio en el caso de Ecuador y Perú:
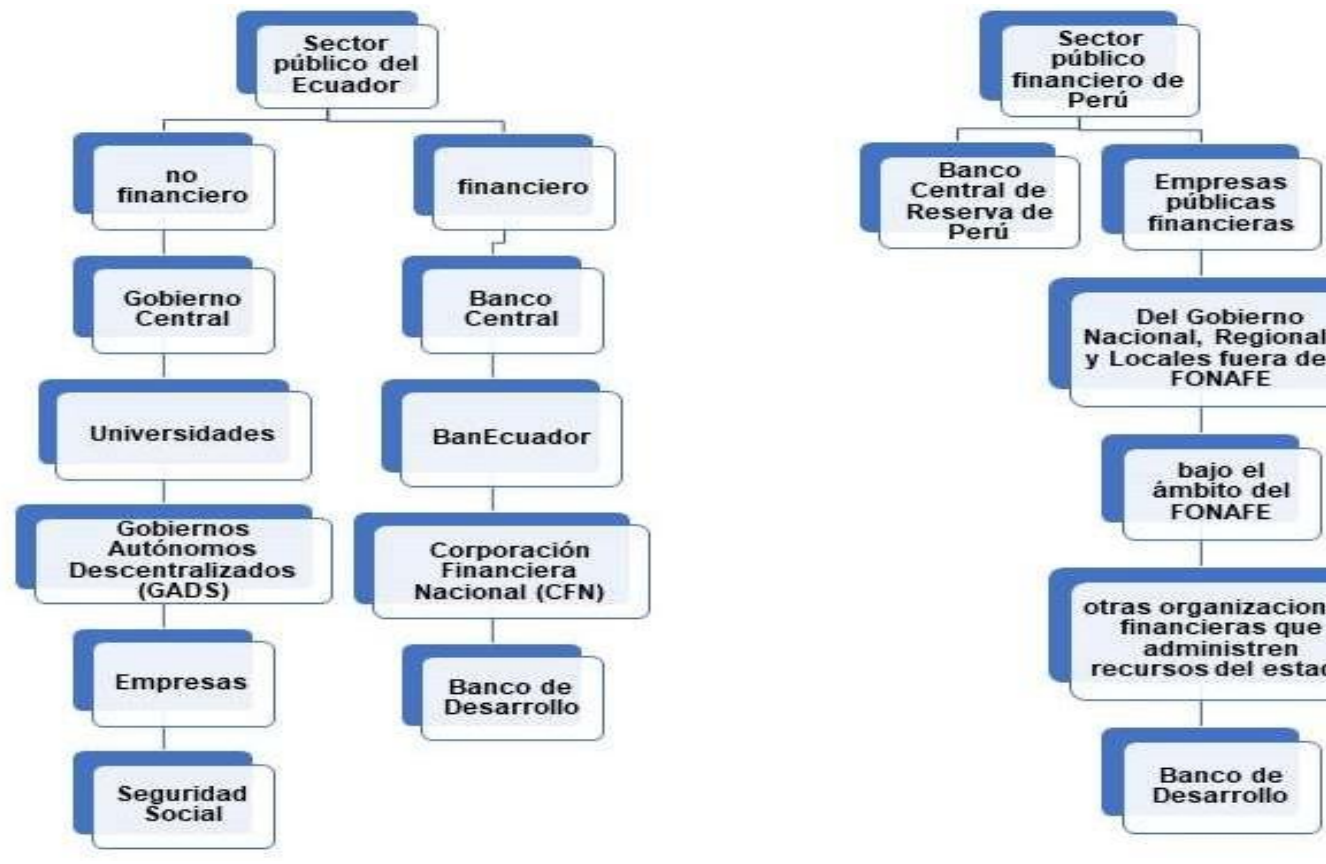

Figura 1. Clasificación del sector público en Ecuador y Perú. Fuente: (Asamblea Nacional República del Ecuador, 2008; Foro de Contadurías Gubernamentales de América Latina, 2019). 
Como un complemento de lo antes citado, se debe indicar que Perú también posee una clasificación con respecto al sector público no financiero puesto que cuenta con entidades conformadas por el poder ejecutivo, legislativo y jurídico, el Ministerio Público, Jurado Nacional de Elecciones, Oficina Nacional de Procesos Electorales, Registro Nacional de Identificación y Estado Civil, Consejo Nacional de la Magistratura, Defensoría del Pueblo, Tribunal Constitucional, Contraloría General de la República, Superintendencia de Bancos, Seguros y Administradora Privadas de Fondos de Pensiones; las Universidades Públicas; los Gobiernos Regionales y Locales; y, organismos públicos de los niveles de gobierno regional y local.

Además, está conformada por empresas públicas no financieras tanto del gobierno como aquellas bajo el ámbito del Fondo Nacional de Financiamiento de la Actividad Empresarial del Estado - FONAFE. Al final, y no menos importantes se ubican los organismos no financieros que manejan recursos públicos como lo son la caja de pensiones para militares y policías, el seguro de salud y administrador de fondo público estatal. (Foro de Contadurías Gubernamentales de América Latina, 2019).

Es así que, para la implementación de las Normas Internacionales de Contabilidad para el Sector Público al ser su aplicación de carácter contable, se deben tomar en cuenta algunos conceptos con respecto a los estados financieros, como lo menciona (AblanBortone, 2013), en donde los resultados de la adopción de estas normas para el sector público significaría una mejora en los estados financieros tanto en su calidad como en la toma de decisiones sobre el uso de recursos públicos de manera que se informe con transparencia.

Para (Sánchez \& Pincay, 2013) los estados financieros públicos constituyen un instrumento importante para la formulación de decisiones en el ámbito de la gerencia, así como también para los empresarios, ya que su presupuesto a más de evidenciar las decisiones tomadas, presenta la información en orden y con armonía, por lo que se concluye en que la misma es totalmente confiable. Otro punto de vista con respecto a los estados financieros es manifestado por la (Firma auditora independiente EY, 2017) 
donde se indica que varios países han realizado estudios de brechas dentro del proceso de cambio a Normas Internacionales de Contabilidad para el Sector Público, aspecto que permite comparar diferentes prácticas contables entre países y así comprender de mejor forma la información publicada en los estados financieros. Además, ayuda a reconocer las áreas que requieren de acción y los retos que deben prevalecer.

Dentro de esta perspectiva, (Sánchez \& Pincay, 2013) señalan que la información financiera es reflejada en su mayoría por la parte presupuestaria, ya que considera el principio de devengado y la maneja como valores acumulados; situación que debería modificarse en base a las experiencias manifestadas por varios países en la aplicación del principio antes mencionado, así como el de partida doble. En este mismo contexto, (Curiqueo-Ahumada, Estay-Mondaca \& Fernández-Rozas, 2017), manifiestan que la información financiera de las entidades públicas permite a los beneficiarios conocer los recursos económicos con los que dispone, también, el origen de su financiamiento, así como su liquidez y solvencia. Además, permite tener un detalle de los gastos que se han realizado para obtener bienes y/o servicios, la suficiencia de sus ingresos para cubrir los diversos requerimientos; así mismo, los autores afirman que para que exista calidad en la información al momento de su elaboración se debe contemplar características como la relevancia de la misma, la comprensión, fidelidad en su representación, que se la pueda comparar y verificar.

Mientras tanto, (Velásquez-Graciano \& Pérez-Morales, 2018), señalan como el objetivo primordial de la información financiera la utilidad que se le dé a la misma por parte de sus usuarios, por ejemplo para la elaboración de informes de rendición de cuentas, evaluaciones de cumplimiento de metas y recursos comprometidos, entre otros. Por otro lado, para el Foro de Contadurías Gubernamentales de América Latina (2019) la información financiera no debería ser únicamente una representación de los hechos económicos, sino que las mismas, deben ser reflejadas contablemente en concordancia a sus particularidades y realidad; no solamente como una interpretación legal o presupuestaria. 
Finalmente, cabe resaltar que, con el afán de alcanzar las metas trazadas, las instituciones públicas debe contemplar los elementos característicos que todo estado no financiero debe poseer; ya que por medio de este documento revelará los resultados de transacciones y hechos que se encuentran intrínsecamente relacionados con la situación financiera de sus activos, pasivos, patrimonio, y de sus ingresos y gastos tanto patrimoniales como presupuestarios (Curiqueo-Ahumada, Estay-Mondaca \& FernándezRozas, 2017).

\section{Problemas y experiencias de la adopción de NICSP en América Latina}

Como parte de la adopción de las Normas Internacionales de Contabilidad para el Sector Público se presentaron algunas novedades, así lo explican (Ablan-Bortone, 2013), pues describen como un problema de gran magnitud la pérdida de responsabilidad por parte del Consejo de Normas Internacionales de Contabilidad para el Sector Público (IPSASB), por cuanto no ha sido considerado en la implementación de las NICSP. Esta función ha sido asignada a los gobiernos por medio de sus organismos encargados de la emisión de normas en contabilidad, con el objetivo de elaborar los modelos contables para cada uno de ellos como corresponde. También un punto de quiebre en esta convergencia es la incidencia del presupuesto dentro del control público puesto que le resta valor al detalle financiero al momento de formular decisiones. Por último, concluyen que los países que asuman la convergencia a las NICSP deben superar inconvenientes en este proceso sobre todo los vinculados con la preparación de los profesionales, varias reformas en el aspecto legal y reglamentario, renovaciones y cambios de sus sistemas informáticos y sin duda, en los procesos contables donde serán más notorios los cambios y retos.

En este mismo contexto, (Bergmann \& Labaronne, 2013) manifiestan la determinación de una dificultad primordial, para algunos países, cuyo sistema se desarrollaba bajo aspectos de contabilidad de caja y de devengo, es decir, aplicando un principio mixto, lo cual daba origen a una inseguridad en el momento de registrar sus transacciones; sin embargo, al final se optó por el principio del devengado, lo cual motivó a realizar 
reformas de su normativa para acoplarlas a estos fines. De igual manera, la (Firma Auditora Independiente EY, 2017) expresa como un inconveniente el cumplimiento de fechas en el cronograma para la presentación de estados financieros comparativos al 31 de diciembre de 2016, lo cual fue prorrogado para el año 2017, por ejemplo, para el Gobierno Central en Perú en el caso de las NICSP 17 y 25, siendo la causa la modificación en algunos puntos determinados por las normas internacionales, por ende, dando como resultado diferencias.

Dentro de este marco, el (Foro de Contadurías Gubernamentales de América Latina, 2019), indica que en el caso de Perú se ha aplicado un sistema de devengo modificado; no obstante, este criterio da lugar a que ciertos activos o pasivos no sean reconocidos. Así también, sus estados financieros son estructurados aplicando el devengado, con la excepción del impuesto a la renta y otros impuestos los cuales son reconocidos a su presentación o a su percepción. Otro aspecto a considerar es que a las entidades estatales se les designó efectuar un análisis de las brechas entre la normativa contable aplicada y lo solicitado por las NICSP, y adicional a esta tarea la evaluación e implementación de su adopción, actividades que no sólo significarán dedicación de tiempo sino un desembolso importante de recursos para su ejecución.

De igual manera, (Plata-Sandoval, 2016), califica como uno de los retos a superar en esta convergencia el reconocimiento y revisión completa del patrimonio, por cuanto se debe integrar todo lo que se posee tanto en cantidades como en valores, sin omitir las normas para depreciarlos, amortizarlos o por su deterioro, de manera que se cuente con un plan de cuentas adecuado concordante con sus clasificadores ajustados.

Así también, la (Contraloría General de la República, 2017) como órgano de control en Costa Rica, da a conocer por medio de su informe de evaluación con respecto a la aplicación e implantación de la normativa en las entidades municipales, la presencia de limitantes que han incidido en el cumplimiento de su implementación, los cuales radican en la ausencia de interés sobre el tema normativo por parte de las autoridades de las entidades analizadas, y por supuesto la falta de participación del personal al no colaborar en este proceso. 
Por su parte, (Reyes, 2016) expresan la experiencia de El Salvador en este paso a la armonización de la nueva normativa, donde se evidenció situaciones que interferían con la fase de transición como la omisión de un estudio previo fundamentado en un plan de acción, sumado a ello la carencia de recurso humano y sustento financiero para este proyecto.

En esta perspectiva, (Luciani-Toro, Zerpa-de-Hurtado \& Castellanos-Sánchez, 2019), manifiestan que Venezuela ha identificado un principal reto en esta convergencia, puesto que en la actualidad no cuenta con normas técnicas bajo NICSP, lo cual implica que no posee una actualización de la misma en base a las disposiciones y recomendaciones del IPSASB, producto de esta acción su sistema contable no se encuentra integrado a nivel general.

Cabe destacar lo indicado por (Araya-Leandro, Caba-Pérez \& López-Hernández, 2016), con respecto a la problemática encontrada en Nicaragua, en la implantación de la nueva normativa, ya que no se han adoptado medidas específicas para armonizar la legislación y las prácticas nacionales en contabilidad gubernamental como lo indican las IPSASB; así también, no se ha considerado valores para este proceso, ni se ha previsto la necesidad tecnológica para la incorporación de sistemas informáticos contables.

De igual forma, (Araya-Leandro, 2011) señala que los países centroamericanos en su esfuerzo por incorporarse a las exigencias que plantea las NICSP, han realizado una comparación de sus estados financieros, sin embargo, no cumplen con los requerimientos que demanda el IPSAS, por lo que deberán ajustar su información incluyendo las respectivas notas en sus estados financieros y mejorar su contenido.

Sobre la base de las ideas expuestas, se puede observar la existencia de dificultades en el proceso de implementación y aplicación de las NICSP, debido a varios factores que influyen en esta transición, debiendo considerarse los esfuerzos tanto humanos como materiales para ser solventados a lo largo de su desarrollo con el objetivo de alcanzar los resultados esperados. 


\section{Los retos en la aplicación de las NICSP}

Los organismos de índole internacional voceros de la convergencia a NICSP, han emitido varias recomendaciones para los países que se encuentran en la transición e implementación de las Normas Internacionales de Contabilidad para el sector público puesto que con ellas se obtendrá una información transparente, y además respaldará la obtención de créditos por parte de instituciones financieras de orden mundial como lo es el Fondo Monetario Internacional (FMI), entidad que desde ya se encuentra con la exigencia de una armonización a NICSP incluso en cualquier tipo de entidades, es decir pública o privada (Lozano-Calero, Narváez-Zurita, Erazo-Álvarez \& Montero-Cobo, 2019). En este contexto, para (Ablan-Bortone, 2013), cada gobierno será el encargado de escoger los estándares para la implementación de las NICSP, así como las entidades emisoras de normas contables serán las responsables, sea de la emisión como de las reformas de la normativa para esta transición; para lo cual podrían contar con la ayuda de las NICSP de manera que se pueda efectuar una comparación con resultados favorables. Para el caso de países que aún no desarrollan normas para sus entidades públicas habría una mayor facilidad de adaptabilidad.

Por otro lado, (Maurer \& López, 2013),.mencionan el caso práctico aplicado en Guatemala, país que para mediados del año 2020 ya debería culminar su proceso de implementación a las NICSP, sin embargo, todavía enfrenta algunos retos en esta convergencia, por lo que debe optimizar sus sistemas de información, proveerse del personal necesario; no obstante debido al corto presupuesto del que dispone posee una complicación tanto para la búsqueda de personal así como para fijar esta meta enmarcada a perfiles de personas preparadas o que conozcan sobre el tema. Además, deberá acogerse al manejo conceptual de carácter internacional formulados por el Banco Interamericano de Desarrollo, Banco Mundial y el Departamento del Tesoro de Estados Unidos.

Al respecto, (Ortega-Aguilar, Sepúlveda-Pérez \& Muñoz-Sánchez, 2018), manifiestan como ejemplo en el caso de Colombia que la implementación de las NICSP han demostrado aún no estar listos para sobrellevar los desafíos de esta convergencia debido 
Lourdes Patricia Illescas-Guillén; Cecilia Ivonne Narváez-Zurita; Juan Carlos Erazo-Álvarez

a la falta de conocimiento sobre los valores que se debían requerir para capacitación, tecnología, recursos y estudio necesarios para esta transición, siendo para ello un pilar fundamental el contador; es por ello que se debería formar a los nuevos profesionales de manera que se encuentren en la capacidad de comprender y ser capaces de acoplarse a estas innovaciones contables.

Al abordar este tema, la (International Federation of Accountants, 2019) resalta a nivel mundial la toma de decisiones en el ámbito financiero tanto para los gobiernos como para cada una de las entidades públicas que la conforman como uno de los aspectos que influye en la ciudadanía; así como la información incompleta y la falta de proyectos y programas que sustenten lo ejecutado.

Considerando estos puntos, el International Public Sector Accounting Standards Board (IPSASB) ha realizado el análisis sobre varios retos que deberá afrontar en su aplicación desde el año 2019 al 2023, siendo estos las brechas clave, las normas desactualizadas frente a versiones de las NIIF, el acceso a los estados financieros para la ciudadanía en general, la capacidad de restricciones en la adopción, la asesoría en reformas de la normativa aplicable y el fortalecimiento de una base acumulativa de información de manera que pueda ser utilizada como evidencia para las reformas que se deban efectuar. Por su parte, (Lozano-Calero, Narváez-Zurita, Erazo-Álvarez \& Montero-Cobo, 2019), indican que si bien uno de los objetivos de la convergencia a las NICSP es la obtención de información confiable de la situación financiera de las entidades de gobierno para la toma de decisiones, es importante que cada entidad cuente con una adecuada planificación y control periódico de sus operaciones. Es por ello, que para que exista una efectiva armonización de las NICSP se debe considerar internamente un control efectivo, de manera que los resultados sean eficientes y de calidad. 


\section{METODOLOGÍA}

El presente análisis se fundamentó en un diseño de investigación no experimental, puesto que las variables fueron observadas y analizadas, sin manipular intencionalmente las mismas, el estudio se basó en una revisión documental y la aplicación de entrevistas para determinar el estado en el que se encuentra actualmente la implementación de las NICSP en Perú y Ecuador, respectivamente. Al tratarse de una investigación no experimental, el diseño de la misma fue transversal, puesto que la recolección de información y su análisis se desarrolló en un momento único en el tiempo (Hernández Sampieri, Fernández Collado, \& Baptista Lucio, 2014).

En lo que corresponde a los instrumentos, se elaboró una entrevista semiestructurada. Se consideró para el caso de Ecuador como población de estudio las instituciones públicas no financieras ubicadas en la ciudad de Cuenca, teniendo como unidad de análisis el Gobierno Autónomo Descentralizado del cantón Cuenca y el Hospital Regional Vicente Corral Moscoso (Calle-Calle, Narváez-Zurita \& Erazo-Álvarez, 2019).

\section{RESULTADOS}

\section{Implementación de las NICSP en el sector público no financiero}

La convergencia a las Normas Internacionales de Contabilidad para el sector público es el resultado a la búsqueda de poseer una contabilidad gubernamental íntegra bajo una normativa uniforme, la cual permitirá obtener estados financieros correctos y pertinentes que contribuyan en gran medida a la transparencia en el uso y manejo de los recursos públicos, además de evaluar el cumplimiento de obligaciones y metas trazadas, medida en la eficiencia y eficacia de los actos de cada gobierno, garantizando su credibilidad ante futuros inversionistas tanto nacionales como extranjeros (Ministerio de Economía y Finanzas Públicas, 2019).

En este sentido, para la implementación de las NICSP en el sector público no financiero se requiere de varios actores como son el ente rector de Finanzas de cada país, que es quien da las directrices a los responsables financieros en cada una de las entidades a 
su cargo. Por tal razón, en Ecuador mediante las entrevistas realizadas a la responsable de Contabilidad del Hospital Vicente Corral Moscoso, al Director General Financiero y Contador General del Gobierno Autónomo Descentralizado Municipal del cantón Cuenca, se pudo evidenciar novedades en la aplicación de los procesos para la implementación de las NICSP.

\section{Conocimiento sobre NICSP}

Esta transición a la nueva normativa ha puesto a todos los países del mundo dentro de un proceso de innovación, por ello es vital el conocimiento de las mismas, es así que en esta variable se pudo determinar que los servidores responsables y relacionados conocen las normas que servirán para el registro de hechos económicos como parte de la presentación de estados financieros; existiendo por parte del Ministerio de Finanzas un instructivo que deberán aplicar para esta convergencia.

\section{Experiencias del proceso de transición}

Considerando que todo cambio genera reacciones de diferente índole, se tomó en cuenta la medición de las experiencias de cada entidad en este proceso de transición normativa, las cuales reflejaron el cumplimiento de directrices del ente rector, con un inicio proyectado a partir del año 2020; sin embargo, las entidades han realizado ajustes en cuentas de bienes e inventarios y acumulación de obras como operaciones preparativas para la convergencia.

\section{Nivel de aceptación al cambio}

Al ser considerado un cambio innovador, se examinó el nivel de aceptación del mismo, por un lado, las entidades lo han tomado de manera positiva como una mejora de la calidad y comparabilidad de la información en el sector público; y la contraparte se debe a que, a pesar de que existe un avance no se tiene la claridad en las disposiciones emitidas por el ente rector. 


\section{Cambios significativos en la entidad producto de la aplicación de las NICSP} Complementando lo manifestado, se observó que estas entidades se guían por el objetivo de esta transición, es decir, el obtener estados financieros que proporcionen información para el análisis de la sostenibilidad de la política fiscal, lo cual apoyará la toma de decisiones fiscales y la lucha contra la corrupción y la mala gestión; no obstante, se recalca la falta de información por parte del Ministerio de Finanzas, ya que hasta la presente fecha no remite el nuevo catálogo de cuentas contables para su conocimiento y aplicación.

\section{Etapa de implementación}

Todo proceso para su implementación debe ser realizada por fases, ya que deben irse desarrollando ciertos mecanismos y regulaciones para su incorporación; por ello ha sido necesario indagar las etapas en las que se encuentran las entidades del sector público no financiero dentro de esta convergencia, obteniendo como resultado un retraso en su inicio, ya que se encontraba planificado para el segundo trimestre del año 2020, según las últimas directrices del ente rector, a pesar de esta particularidad, las entidades han cumplido con la fase de ajustes, reclasificación y revalorización de activos dispuesta por el Ministerio de Economía y Finanzas.

\section{Capacitación}

Al tratarse de una normativa nueva es necesario que los servidores y el personal de las entidades del sector público no financiero reciban la capacitación correspondiente que complemente sus conocimientos, con el objetivo de que puedan familiarizarse con las tareas y ser un soporte ante inconsistencias o problemas que puedan surgir. Por esta razón, se analizó este parámetro, que, si bien fue cubierto por el ente rector; por parte de las entidades que lo receptaron lo calificaron como insuficiente, ya que aquellos servidores que asistieron deberán replicar los temas impartidos a sus compañeros; adicional a este punto, se les indicó que una nueva capacitación arrancaría desde el segundo trimestre del año 2020, situación que no se realizó. 


\section{Experiencia profesional de los servidores públicos en NICSP}

La experiencia y el conocimiento contable en las entidades públicas es una variable necesaria de medir para la transición a NICSP, existiendo positivismo en las entidades de que su personal tiene los conocimientos en el manejo de Contabilidad Gubernamental para abordar con facilidad este cambio.

\section{Aspectos para mejorar en este proceso}

Dentro de todo proceso, y más aún en el de NICSP de carácter innovador, se presentarán recomendaciones y sugerencias a lo largo de su desarrollo, los cuales deberán ser tomados en cuenta para continuar de mejor forma con una exitosa implementación. Es del caso, que las entidades del sector público no financiero establecieron como principal punto la capacitación, así como el poder contar con un mecanismo para consultas como lo es la denominada mesa de ayuda en la ciudad de Cuenca, ya que actualmente sólo funciona en la matriz que se encuentra en Quito.

\section{Estrategias implantadas en esta convergencia}

Con el fin de conseguir los mejores resultados en el proceso de transición a NICSP, la aplicación de estrategias dentro de las entidades fue una premisa que debía ser sujeta a medición, teniendo como resultado algunas acciones efectuadas por las entidades tales como reuniones para socializar la implementación de las NICSP y el nuevo sistema con las autoridades de la entidad; así también el desarrollo de procesos cumpliendo con las directrices del ente rector como por ejemplo la depuración de saldos.

\section{Ventajas y Desventajas en este proceso}

Se midió el nivel de beneficio/perjuicio de este proyecto de convergencia, en el que las entidades señalaron algunas ventajas de la implementación de las NICSP como el fortalecimiento de la transparencia, eficiencia y rendición de cuentas, la puesta enmarcha de una campaña de gestión de cambio y motivación en las entidades del sector público, 
Lourdes Patricia Illescas-Guillén; Cecilia Ivonne Narváez-Zurita; Juan Carlos Erazo-Álvarez con el fin de lograr un compromiso en la implementación de las NICSP; no obstante, como desventaja se indica el poco o nulo apoyo del ente rector.

\section{Metas institucionales dentro de esta transición}

Este proceso de transición requiere contar con objetivos y metas que determinen y promuevan una implementación eficiente; por lo que se consideró analizar este aspecto en las entidades del sector público no financiero; producto de ello, se evidenció que las instituciones determinaron las siguientes metas para este proceso de implementación: el incrementar la eficacia, eficiencia, calidad y transparencia en la gestión de ingresos, gastos y financiamiento del sector público; así como preparar para el 2020 los primeros estados financieros de acuerdo a la nueva normativa NICSP.

\section{Directrices del ente rector}

En este proceso de convergencia a NICSP, existe un responsable en cada país para llevar a cabo esta transición, en este caso como se manifestó al inicio de este apartado recae sobre el Ministerio de Economía y Finanzas, por lo que fue importante indagar si existieron las directrices correspondientes dictaminadas a las entidades del sector público no financiero; este indicador permitió establecer que las entidades disponen de un instructivo para la aplicación de los diferentes procesos y registros contables en base a las NICSP a través de la herramienta informática SINAFIP, lo cual les permitirá el manejo transparente del gasto público; sin embargo hasta la presente fecha no se ha iniciado esta actividad.

\section{Análisis aplicación NICSP en Perú}

En el caso de Perú, se evidenció un estudio efectuado por el Banco Interamericano de Desarrollo junto con la firma privada EY sobre el estado de adopción de las Normas Internacionales de la Contabilidad para el Sector Público (NICSP), encontrándose con procesos pendientes como: declaraciones expresas de las NICSP que están siendo aplicadas, datos de los estados financieros respecto a variaciones y su incidencia en el ámbito de las finanzas, el uso de aplicativos informáticos creados para el efecto, 
Lourdes Patricia Illescas-Guillén; Cecilia Ivonne Narváez-Zurita; Juan Carlos Erazo-Álvarez compromiso de la Dirección del Ministerio de Economía y Finanzas para la preparación de un plan de acción que considere como ejes primordiales las políticas contables, tecnología, capacitación de sus servidores y la implementación de sistemas Government Resource Planning (GRP) de nivel mundial.

La integración de un comité de usuarios pendientes en la implementación y coordinarán con los órganos rectores de la administración financiera y el Órgano Superior de Control, y la elaboración de procesos de contabilidad con base en las NICSP llevados a casos prácticos en la rutina diaria. De igual manera, se citan algunas ventajas entre las más destacadas encontramos la obtención de información transparente y confiable que contribuya a una mejor toma de decisiones de Estado, así como en la rendición de cuentas y la evaluación en cuanto a la distribución de recursos con eficiencia y eficacia mediante indicadores de gestión, lo que permitirá prever financiamientos futuros de ser requeridos. (Firma auditora independiente EY, 2017).

Tanto en Ecuador como en Perú, se evidencia la presencia de dificultades en el proceso de implementación de las NICSP, siendo la falta de capacitación la más sentida por los servidores. Así también se puede observar que los dos países se encuentran a expensas de las directrices de su órgano rector para la aplicación de normas y guías que les permitan poner en marcha la aplicación de las NICSP. En el caso de Perú, ya se han elaborado estados financieros aplicando las Normas Internacionales de Contabilidad para el Sector Público; sin embargo, en Ecuador según lo mencionaron los entrevistados de acuerdo a las directrices emitidas por el órgano rector se realizarán los primeros registros contables aplicando la norma a partir del 1 de enero del 2020. 


\section{PROPUESTA}

Partiendo de los resultados obtenidos en el presente estudio, se propone diseñar un procedimiento metodológico para implementar las NICSP en entidades del sector público no financiero, el mismo que estará conformado por 4 etapas consideradas claves en esta transición como son el plan de acción que permitirá determinar la situación actual del proceso, como segundo paso se formularán las estrategias que llevarán a una implementación exitosa y de calidad, un tercer aspecto estará direccionado a la detección y definición de posibles obstáculos o problemas que se han presenciado en la implantación de esta normativa; finalmente, con el análisis y detección de problemas se podrán establecer objetivos y formular programas para disminuir el impacto que puedan causar determinadas barreras en la aplicación de las NICSP en las entidades del sector público no financiero, como se puede observar a continuación en la figura 2:

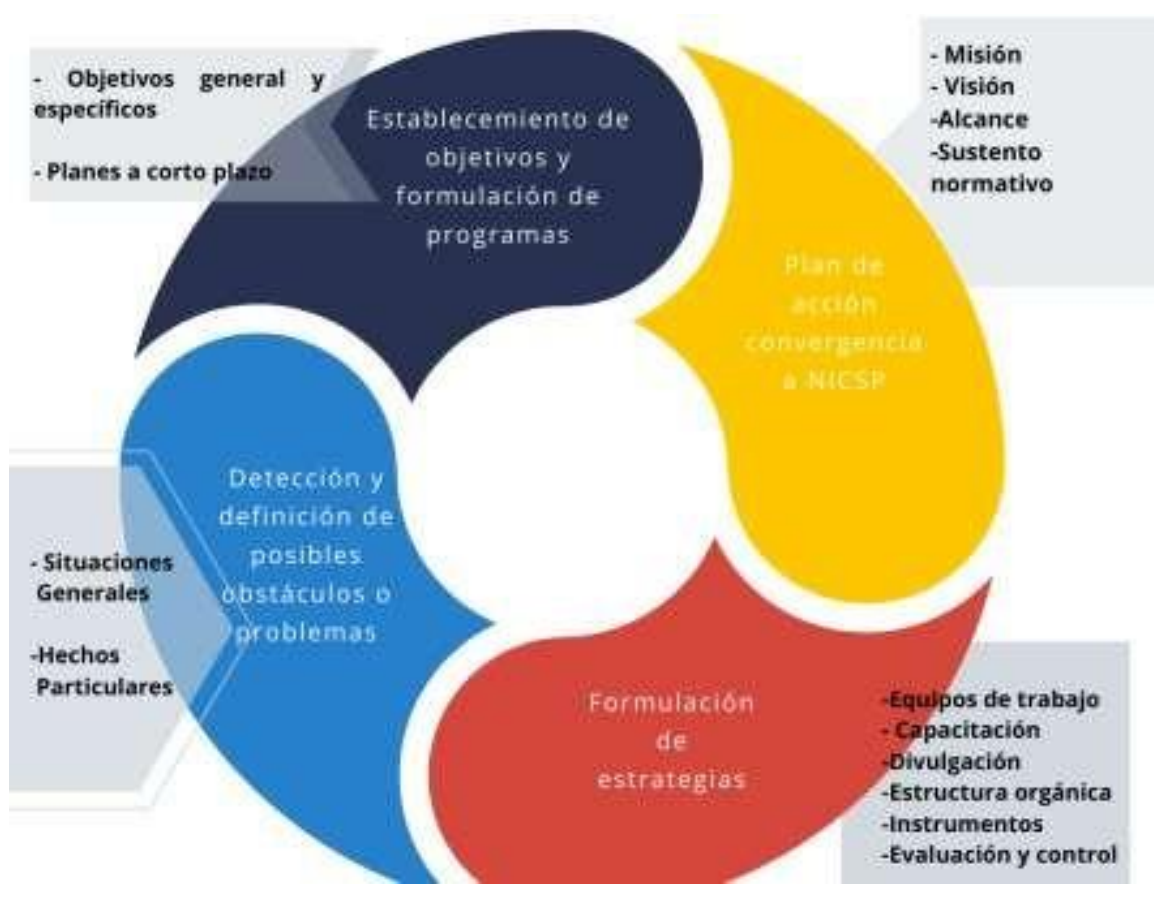

Figura 2. Procedimiento metodológico para la implementación de las NISP en entidades del sector público no financiero. 


\section{Plan de acción}

Al ser la convergencia a NICSP un proceso complejo, ya que presenta cambios radicales desde la parte legal hasta su desarrollo práctico, es necesario realizar un análisis de la situación actual en la que se encuentra este proceso en cada entidad del sector público no financiero, para lo cual se deberá definir la misión, visión, alcance con sus actores o responsables y el sustento normativo que será la guía legal de este proyecto interno.

\section{a) Misión}

Este debe ser un precepto que deberán llevar consigo los servidores que estarán al frente de este reto como responsables directos de este proceso, por lo que se propone la siguiente misión:

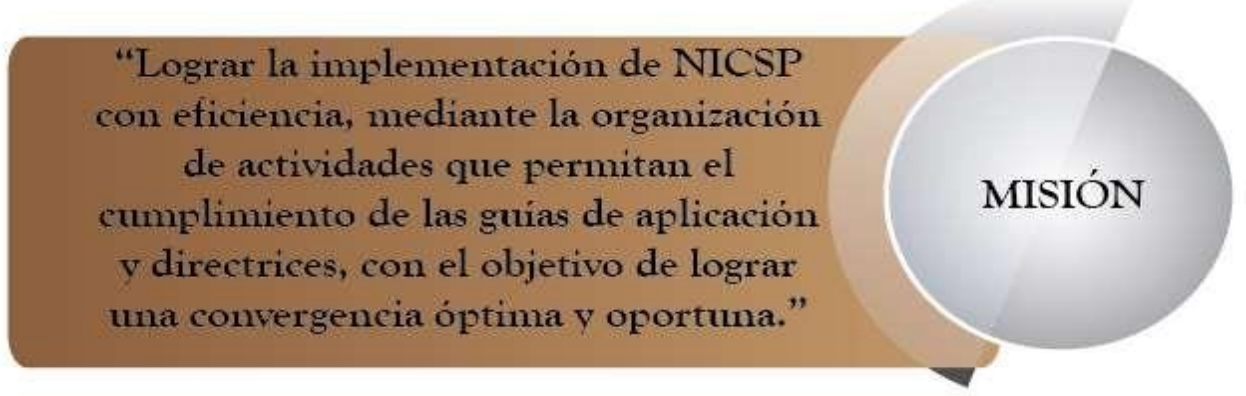

Figura 3. Misión

\section{b) Visión}

Al ser la visión aquellos valores que se esperan sean reconocidos en el futuro, con respecto al tema de transición a NICSP para las entidades del sector público, se definiría como: 


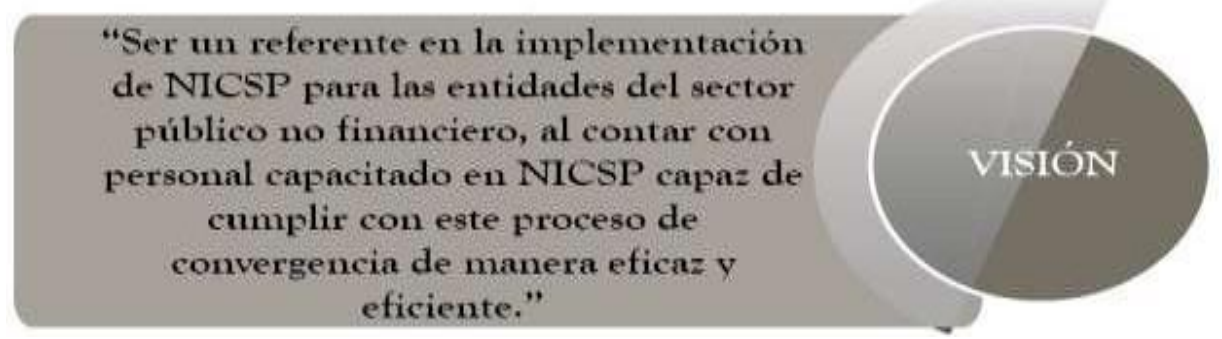

Figura 4. Visión

\section{c) Alcance}

Este aspecto ha sido planteado en base al nuevo sistema de administración financiera (SINAFIP) desde su visión funcional, puesto que integra los componentes: política y programación fiscal, ingresos, presupuesto, endeudamiento público, contabilidad gubernamental y tesorería.

\section{Guía de Aplicación}

Este documento proporcionará la información necesaria sobre la implementación de las NICSP para las entidades del sector público no financiero, el cual estará conformado por: antecedentes, base legal, ámbito de aplicación, procesos generales y específicos para cada cuenta, así como la proyección de los estados financieros de transición a NICSP, todos estos detalles elaborados en base a la NICSP 33 Adopción por primera vez de las Normas Internacionales de Contabilidad del Sector Público de Base de Acumulación (o devengo) (NICSP).

Por consiguiente, los actores relacionados a determinarse serán: directos para el presente caso los Directores Financieros o sus delegados como responsables administrativos de la implementación de las NICSP, así como los responsables operativos que efectuarán los procesos de implementación tarea que recaería en los Contadores; $y$, como actores de control lo conformarían las personas que van a disponer de la información para su uso y revisión como son el Ministerio de Finanzas, Subsecretaria de Contabilidad Gubernamental, y finalmente, los usuarios finales como la ciudadanía en general que podrá observar la información producto de esta 
Lourdes Patricia Illescas-Guillén; Cecilia Ivonne Narváez-Zurita; Juan Carlos Erazo-Álvarez convergencia a través del link de transparencia que disponen todas las entidades públicas, quienes deben publicar la información de acuerdo a lo dispuesto por la Ley de Transparencia y Control de la Información.

\section{d) Sustento Normativo}

Todo proceso metodológico debe tener su correspondiente justificativo y base legal, por consiguiente este procedimiento para la implementación a NICSP se fundamenta en las Normas Internacionales de Contabilidad del Sector Público expedidas por las IPSASB (Consejo de Normas Internacionales de Contabilidad del Sector Público), el COPLAFIP (Código Orgánico de Planificación y Finanzas Públicas) y su reglamento, Normativa de Contabilidad Gubernamental, el sistema SINAFIP, clasificador presupuestario y catálogo de cuentas contables, el cual deberá estar ajustado a la nueva normativa.

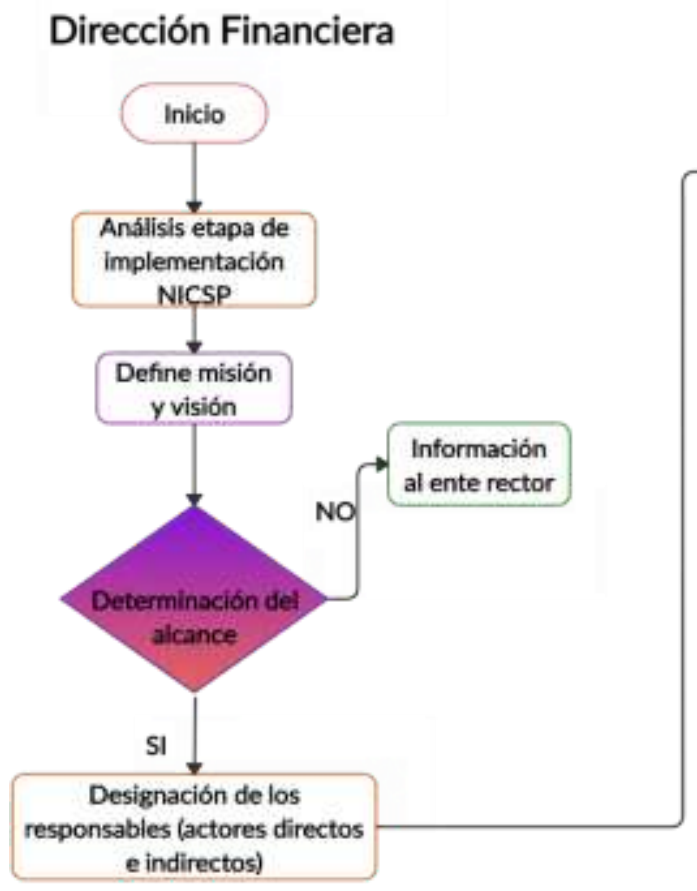

\section{Contabilidad}

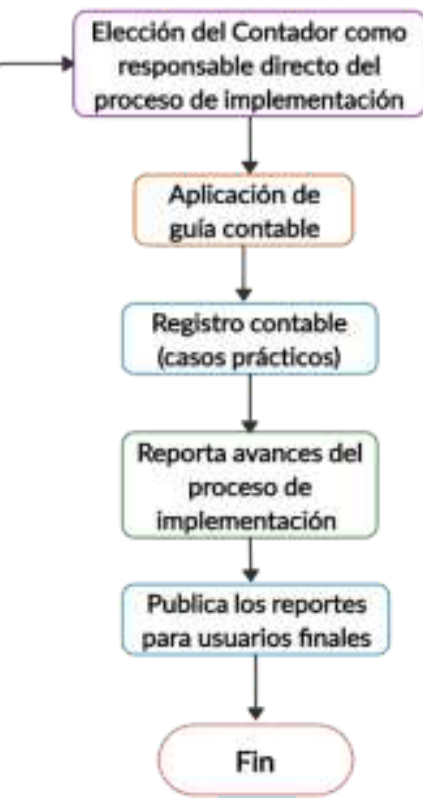

Figura 5. Plan de acción para implementación de procesos a NICSP 


\section{Formulación de estrategias}

Para iniciar con esta actividad es necesario conformar un equipo de trabajo, el cual se recomienda se encuentre integrado por personal del Departamento Financiero encabezado por su director o delegado, de manera que se pueda dar continuidad y seguimiento en la ejecución del plan de acción y las estrategias metodológicas que se van a aplicar entre actores directos e indirectos, para lo cual se deberá reconocer aspectos como la disponibilidad de recursos y tiempo, el apoyo con el que se cuenta por parte de la entidad, así como la necesidad de involucrar al personal relacionado en esta transición.

\section{a) Capacitación}

Al ser la capacitación un punto débil dentro de este proceso de implementación, se debe considerar el mismo como de vital importancia para lograr que los servidores de las entidades del sector público no financiero obtengan los conocimientos y destrezas requeridas para la aplicación efectiva de las NICSP, a través de talleres tanto teóricos como prácticos de la normativa a implementar para unificar criterios. La planificación de reuniones de trabajo deberá ser debidamente programada y socializada por lo que se recomienda el uso de medios tecnológicos como una página web o por medio de un oficio circular a los responsables financieros de cada entidad.

\section{b) Divulgación}

La divulgación deberá ser manejada como una estrategia complementaria ya que no sólo se la realizaría de manera interna en las entidades del sector público sino también al público en general, con el propósito de generar conocimiento y apoyo a este proyecto; el cual podrá ser realizado por medios digitales, visuales y escritos.

\section{c) Estructura Orgánica}

En su mayoría, las entidades del sector público no financiero cuentan en su estructura orgánica con un departamento financiero conformado por un equipo de profesionales 
Lourdes Patricia Illescas-Guillén; Cecilia Ivonne Narváez-Zurita; Juan Carlos Erazo-Álvarez responsables en diversas áreas (presupuestaria, contable, financiera), por lo que se debería considerar para esta actividad un ejecutor directo del proceso de convergencia a NICSP, para lo cual se recomienda designar al Contador de la entidad por ser esta persona la que se encontrará directamente involucrada en el registro y manejo de la información, además que esta área es prácticamente el punto clave de esta implantación.

\section{d) Instrumentos}

Para obtener una exitosa implementación de las NICSP, las entidades del sector público no financiero deberán reforzar sus herramientas técnicas contables, es decir, sus controles físicos, efectuando conciliaciones bancarias e inventarios de manera más rigurosa. A pesar de que algunas de ellas vienen dadas por el ente rector por medio de la Normativa de Contabilidad Gubernamental bajo NICSP y el Código Orgánico de Planificación y Finanzas Públicas; aún no se ha publicado el Plan de Cuentas, instrumento fundamental para el desarrollo de este proceso de convergencia por lo que se propone un análisis de las cuentas contables vigentes en las entidades del sector público no financiero y el plan de cuentas propuesto según NICSP, para lo cual se ha tomado como ejemplo un balance de comprobación de una entidad del sector público no financiero (hospital) para este ejercicio.

\section{e) Evaluación y Control}

Una estrategia final a tomar en cuenta será la evaluación y control, puesto que se deberá valorar a las actividades llevadas a cabo desde su inicio, durante su desarrollo, así como al finalizar las mismas; este tratamiento servirá de apoyo para detectar a tiempo errores y tomar los correctivos necesarios a fin de cumplir el objetivo de implantación de las NICSP en las entidades del sector público no financiero con eficiencia y eficacia.

Por consiguiente, se deberán implantar las herramientas de control que permitan conocer si las estrategias utilizadas son las correctas o deberán ajustarse o cambiarse de tal manera que respalden la disminución de errores y se conviertan en una fuente de retroalimentación. Esta particularidad será llevada a cabo por medio de indicadores de evaluación tales como la aplicación de cuestionarios en línea al personal del 
Lourdes Patricia Illescas-Guillén; Cecilia Ivonne Narváez-Zurita; Juan Carlos Erazo-Álvarez Departamento Financiero de las entidades del sector público; así como se les solicitará la entrega de avances de manera periódica, hechos que, además permitirán evaluar el servicio de asesoramiento y acompañamiento brindado por el equipo de trabajo, para corregir problemas y mejorar el servicio y rendimiento en las actividades asignadas.

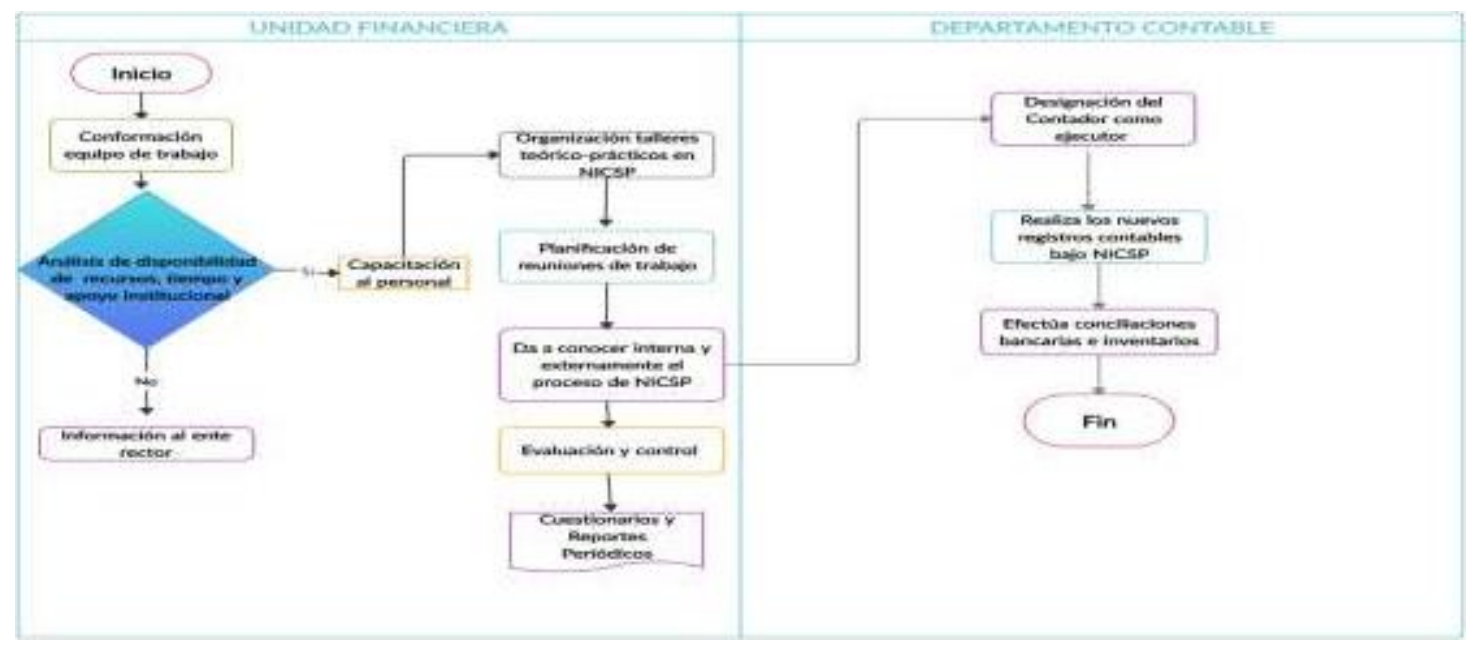

Figura 6. Formulación de estrategias para implementación de las NICSP en entidades del sector público no financiero.

\section{Detección y definición de posibles situaciones problemáticas}

En el desarrollo de este proceso de implantación de las NICSP, las entidades públicas identificarán circunstancias que podrían afectarlo, así también los eventos que deberían ser analizados por ser de relevancia e interés y que podrían constituir riesgos inherentes de las entidades; por ello en primera instancia, las instituciones deberán enfrentar estos probables conflictos, para luego, reportarlos al ente rector y a la Subsecretaria de Contabilidad Gubernamental como responsables del tema de NICSP de manera que consideren estos aspectos. 
Basado en el estudio que se efectuó para el proyecto de convergencia a NICSP, el cual tomó como referencia los reportes de brechas, y la normativa elaborada por la Subsecretaria de Contabilidad Gubernamental y Sistema Nacional de Finanzas Públicas, se pueden identificar dos posibles problemas: situaciones generales y hechos particulares, que deberán tomar en cuenta las entidades al momento de incorporar los procesos a NICSP, entre algunos de ellos podemos mencionar de carácter general la falta de incorporación de NICSP en la normativa contable vigente, ya que se lo ha realizado de manera parcial, no se ha realizado la consolidación de la información financiera por problemas con la herramienta que se utiliza, así como la ausencia de un plan de cuentas con base en NICSP.

Ante estas circunstancias, se reflejan hechos particulares como son la depuración y paso de saldos contables y el desconocimiento para reconocer y medir los principales elementos de los estados financieros ya que aún no se cuenta con una integración de los clasificadores presupuestario con el contable.

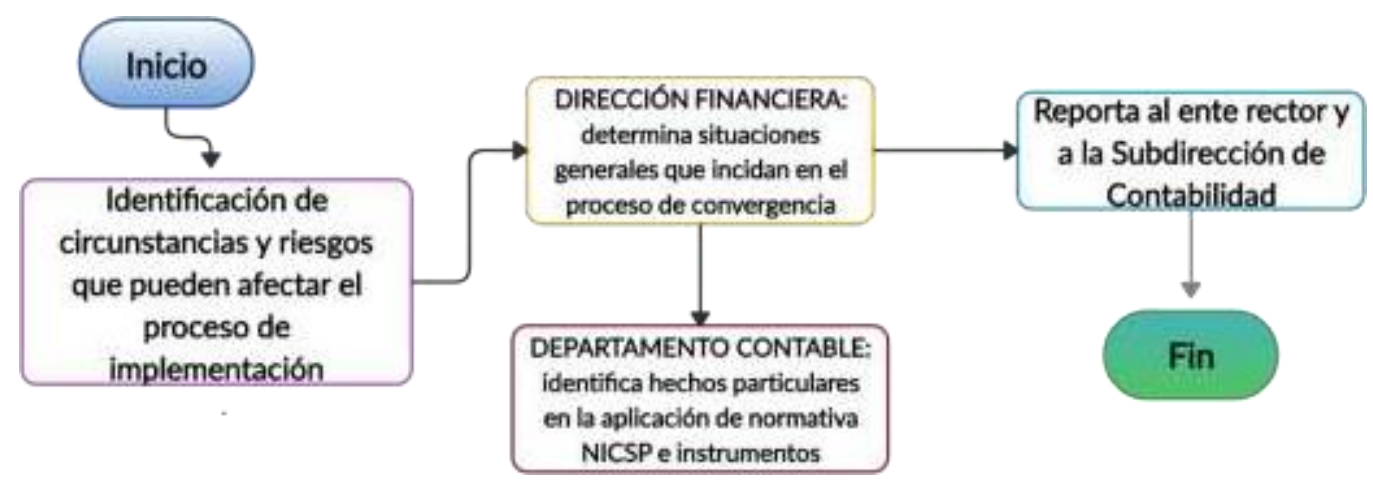

Figura 7. Detección y definición de posibles situaciones problemáticas

\section{Establecimiento de objetivos y formulación de programas}

Las entidades del sector público deberán implantar en esta etapa de transición a NICSP objetivos con la finalidad de obtener una implementación exitosa, identificando tanto objetivos generales como específicos. Como objetivo general se deberá reforzar conceptos y actividades relacionadas con los aspectos contables, por medio de la guía de aplicación que permita direccionar su registro y contabilización en base a la nueva 
Lourdes Patricia Illescas-Guillén; Cecilia Ivonne Narváez-Zurita; Juan Carlos Erazo-Álvarez normativa. En cuanto a los objetivos específicos estos dependerán de los involucrados en la actividad, para el presente caso la actuación recae sobre los actores directos que son las entidades del sector público materia de ese análisis; los cuales deberán cumplir la normativa dispuesta por el ente rector, designar a sus contadores como los responsables directos en esta transición, organizar y definir sus procedimientos contables, apoyarse de asesoría de profesionales en NICSP, informar al ente rector y a la Subsecretaria de Contabilidad Gubernamental sobre cambios en el programa asignado y problemas detectados en el desarrollo de sus tareas.

Para la formulación de programas, se establecerán las funciones que cada entidad deberá realizar en base a las situaciones generales y hechos particulares que fueron detectados como posibles problemas en la etapa anterior, puesto que el cumplir con estos retos constituye un paso esencial que facilitará la convergencia a las NICSP.

Por ejemplo, se desarrollarán políticas contables para el registro de transacciones en base al plan de cuentas propuesto bajo NICSP, mediante la utilización de la respectiva guía de aplicación, actividad que se encontrará a cargo del Departamento Contable.

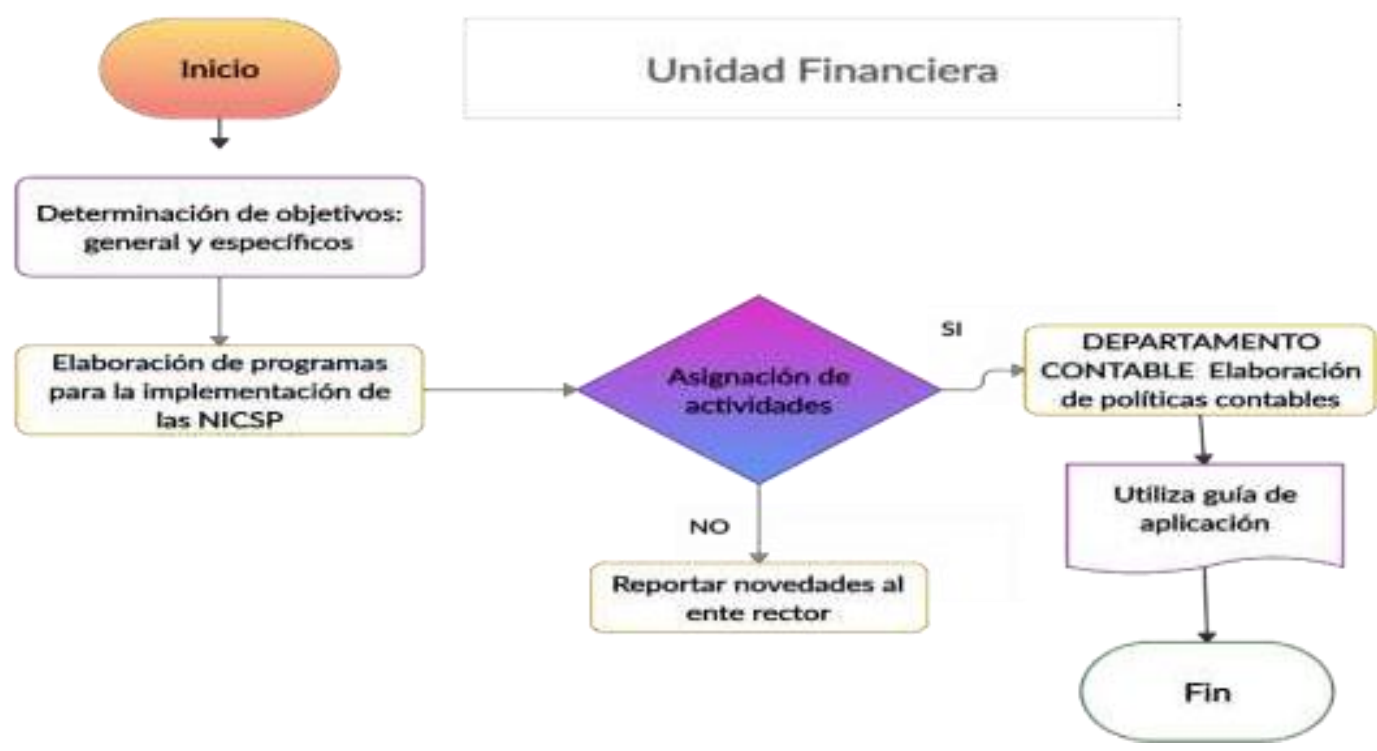

Figura 8. Establecimiento de objetivos y formulación de programas 


\section{DISCUSIÓN}

Actualmente, los países alrededor del mundo y particularmente, en América del Sur, han apostado por la convergencia a las Normas Internacionales de Contabilidad para el Sector Público, debido a que la misma permitirá que las entidades del sector público cuenten con información fiable y completa revelando de esta manera la realidad económica y financiera de sus operaciones, así como facilitará la administración de los recursos públicos, propiciando garantía y calidad en los reportes y el apoyo en la toma de decisiones, generando una apreciación positiva de la economía a nivel internacional (Rico Bonilla \& Díaz Jiménez, 2017).

Dentro de este marco de adopción, se evidencia la presencia de obstáculos en su proceso, es así que varios países han expresado sus dificultades las cuales se resumen en prórrogas para su óptima aplicación, como consecuencia de un descuido en la preparación del personal partiendo desde las máximas autoridades, así como la falta de socialización de la información, la cual contribuiría a un análisis e interpretación del mismo para ser aplicado a la naturaleza de cada entidad (Castañeda, 2018).

La afirmación anterior concuerda con los resultados recopilados a partir de las experiencias de los Departamentos Financieros de las instituciones del sector público no financiero del Ecuador puesto que no existen directrices claras por parte del ente rector para efectuar los respectivos procesos contables y las capacitaciones recibidas al respecto han sido mínimas.

Atendiendo estas consideraciones por parte de las entidades del sector público no financiero, se evidencia la necesidad imperiosa de contar con un procedimiento metodológico de manera que se consiga una adecuada y oportuna implementación de los procesos para la adopción de las NICSP, ya que por medio de esta propuesta se tendrá claridad en los procesos a desarrollar en cada uno de las fases, así como se contará con estrategias que servirán de apoyo para sobrellevar las posibles situaciones problemáticas que se puedan presentar en el desarrollo de la implementación con respecto a esta nueva normativa. 
La propuesta desarrollada en la presente investigación involucra directamente al Departamento Financiero y a su Contador, como actor operativo clave, ya que será el principal ejecutor de este proceso puesto que es el más indicado para direccionar las actividades en cada etapa de esta transición y recomendar los programas que se pueden acoger para una efectiva aplicación, siendo un punto trascendental el contar con los instrumentos para su aplicación, así como el conocimiento y capacitación en NICSP. En cuanto a los instrumentos contables que debe proporcionar el ente rector a cada entidad existe la ausencia de un plan de cuentas bajo NICSP que permita la exactitud y precisión en el registro contable, por lo que dentro del presente análisis se expondrá de manera ejemplificada un análisis relacional de las cuentas más relevantes a dentro del plan de cuentas actual frente a la estructura propuesta con la nueva normativa; puesto que se tiene el propósito de identificar estas cuentas para efectuar un correcto traspaso de los saldos vigentes. (Ministerio de Hacienda Costa Rica, 2013).

\section{FINANCIAMIENTO}

No monetario.

\section{AGRADECIMIENTO}

A las autoridades del Gobierno Autónomo Descentralizado del cantón Cuenca y el Hospital Regional Vicente Corral Moscoso que apoyaron el desarrollo de esta investigación.

\section{REFERENCIAS CONSULTADAS}

Ablan-Bortone, N. (2013). Las Normas Internacionales de Contabilidad para el Sector Público (NICSP): una revisión de los aspectos clave a considerar y de la situación en Venezuela. [International Accounting Standards for the Public Sector (IPSAS): a review of the key aspects to consider and the situation in Venezuela]. Visión Gerencial, 0(2), 221-240. Recuperado de https://n9.cl/mu4k2 
Araya-Leandro, C. (2011). Transparencia financiera gubernamental en los países miembros del Sistema de Integración Centroamericana (SICA). [Government financial transparency in the member countries of the Central American Integration System (SICA)]. InterSedes, 12(23). Recuperado de https://n9.cl/jvha4

Araya-Leandro, C, Caba-Pérez, M, \& López-Hernández, A. (2016). La convergencia de los países centroamericanos con las Normas Internacionales de Contabilidad. [The convergence of the Central American countries to International Accounting Standards]. Revista de Administração Pública , 50 (2), 265-283. https://doi.org/10.1590/0034-7612131665

Asamblea Nacional República del Ecuador. (2008). Constitución 2008. [Constitution 2008]. En C. L. Fiscalización, Constitución 2008 (p. 118). Alfaro, Montecristi: Registro Oficial 20 de octubre de 2008.

Bergmann, A., \& Labaronne, L. (2013). La Armonización contable internacional: El papel del IPSASB y el estado actual de su proceso de reformas. [International accounting harmonization: The role of the IPSASB and the current state of its reform process]. Revista Española de Control Externo. 15(44). 19-29. Recuperado de https://n9.cl/z1095

Calle-Calle, A. I., Narváez-Zurita, C. I., \& Erazo-Álvarez, J. C. (2019). Auditoria en prevención de riesgos laborales y salud ocupacional: Procedimiento sistémico aplicado a la empresa Jasetrón. [Audit in prevention of occupational risks and occupational health: Systemic procedure applied to the company Jasetrón]. Revista Arbitrada Interdisciplinaria Koinonía, 25-55. http://dx.doi.org/10.35381/r.k.v4i2.466

Castañeda, V. M. (2019). El premio de implementar las reformas contables en el sector público promovidas por los organismos multilaterales. [The Prize for Implementing Accounting Reforms in the Public Sector Promoted by Multilateral Organizations]. Revista De Métodos Cuantitativos Para La Economía y La Empresa, 26; 84-103. Recuperado de https://n9.cl/zo77

Contraloria General de la República. (2017). Informe del seguimiento de la gestión acerca de la implementación y aplicación de las Normas Internacionales de Contabilidad para el Sector Público en los gobiernos locales. [Management follow-up report on the implementation and application of International Accounting Standards for the Public Sector in local governments]. Recuperado de https://n9.cl/vnzo 
Curiqueo-Ahumada, M., Estay-Mondaca, N., \& Fernández-Rozas, M. (2017). Análisis de la implementación de la resolución 16/2015, de la Contraloría General de la República referido a los bienes de uso en un servicio público de la región de Valparaíso, periodo 2016. [Analysis of the implementation of resolution 16/2015, of the Office of the Comptroller General of the Republic regarding fixed assets in a public service in the Valparaíso region, period 2016]. Revista de Investigación Aplicada en Ciencias Empresariales, 6

$6 \quad(1)$. https://doi.org/10.22370/riace.2017.6.1.1309

Firma auditora independiente EY. (2017). Estado de adopción de NICSP en los países de Latinoamérica y el Caribe. Recuperado de https://n9.cl/srod

Foro de Contadurías Gubernamentales de América Latina. (2019). Contabilidad Gubernamental en América Latina y convergencia a las Normas Internacionales del Sector Público (NICSP). [Government Accounting in Latin America and convergence to International Public Sector Standards (IPSAS)]. Recuperado de https://n9.cl/6la71

Hernández Sampieri, R., Fernández Collado, C., Baptista Lucio, P. (2014). Metodología de la Investigación. [Investigation methodology]. México: Editorial Mc - Graw - Hill Interamericana. Sexta edición.

International Public Sector Accounting Standards Board (IPSASB, 2019). Plan de trabajo y estrategia 2019 a 2023. Normas globales de entrega. Inspirar la implementación [Work plan and strategy 2019 to 2023. Global delivery standards. Inspire implementation]. Recuperado de https://n9.cl/av0v

Lozano-Calero, G. M., Narváez-Zurita, C. I., Erazo-Álvarez, J. C., \& Montero-Cobo, M. A. (2019). Procedimientos de control y registro contable bajo NIC SP para los activos del Gobierno Autónomo Descentralizado Parroquial de Fundochamba de la provincia de Loja. [Accounting control and registration procedures under NIC SP for the assets of the Parish Decentralized Autonomous Government of Fundochamba in the province of Loja]. Visionario Digital, 3(2.1.), 388-419. https://doi.org/10.33262/visionariodigital.v3i2.1.582

Luciani-Toro, L., Zerpa-de-Hurtado, S., \& Castellanos-Sánchez, H. (2019). Elementos claves de las normas internacionales de contabilidad para el sector público: un aporte para el sistema de contabilidad gubernamental. [Key elements of international public sector accounting standards: a contribution to the government 
accounting system]. Visión Gerencial, O(2), 274-289. Recuperado de https://n9.cl/too8

Ministerio de Economía y Finanzas Públicas. (2019). Instructivo para la convergencia de la Normativa de Contabilidad Gubernamental a NICSP a partir del 1 de enero de 2020. [Instructions for the convergence of Government Accounting Regulations to IPSAS as of January 1, 2020]. Recuperado de https://n9.cl/cxsr

Ministerio de Hacienda Costa Rica. (2013). Metodología de Implementación de las NICSP. [IPSAS Implementation Methodology]. Recuperado de https://n9.cl/t8bl

Maurer, M, \& López, O. (2013). La Experiencia de Adopción de las NICSP en Guatemala. [The IPSAS Adoption Experience in Guatemala]. Recuperado de https://n9.cl/i9v6

Normas internacionales de contabilidad del sector público (NICSP, 2018). Las NICSP en su bolsillo. [IPSAS in your pocket]. Recuperado de https://n9.cl/92yy7

Organización Latinoamericana y del Caribe de Entidades Fiscalizadoras Superiores; Comisión Técnica de Prácticas de Buena Gobernanza. (2015). Características principales de las políticas de Contabilidad Gubernamental de los países cuyas EFS integran la OLACEFS. [Main characteristics of the Government Accounting policies of the countries whose SAls make up the OLACEFS]. Recuperado de https://n9.cl/bnky

Ortega-Aguilar, M, Sepúlveda-Pérez, L, Muñoz-Sánchez, L. (2018). Análisis en las instituciones de educación básica y media de Manizales frente a las necesidades de formación en Normas Internacionales de Contabilidad en el sector público para el año 2016. [Analysis in the institutions of basic and secondary education in Manizales against the training needs in International Accounting Standards in the public sector for 2016]. Investigar y Aprender. http://dx.doi.org/10.22209/ia.n2a05

Ortiz Soto, D. V., Narváez Zurita, C. I., \& Erazo Álvarez, J. C. (2019). Incidencia en la aplicación de la NIC SP17 Propiedad, Planta y Equipo en las Empresas Municipales de Agua Potable. [Incidence in the application of IAS SP17 Property, Plant and Equipment in Municipal Drinking Water Companies]. Cienciamatria, 841-862. https://doi.org/10.35381/cm.v5i1.321 
Lourdes Patricia Illescas-Guillén; Cecilia Ivonne Narváez-Zurita; Juan Carlos Erazo-Álvarez

Plata-Sandoval, J. A. (2016). Implementación de la armonización contable gubernamental en México. [Implementation of government accounting harmonization in Mexico]. El Cotidiano. 189; 27-30. Recuperado de https://n9.cl/srod

Reyes, I. (2016). El nuevo enfoque de la contabilidad gubernamental. [The new approach to government accounting]. Recuperado de https://n9.cl/goxzb

Rico Bonilla, C. O., \& Díaz Jiménez, M. A. (2017). ¿Convergencia de la regulación contable colombiana para las entidades de gobierno con las International Public Sector Accounting Standards (IPSAS)? Una medición de la armonización formal. [Convergence of Colombian accounting regulation for government entities with the International Public Sector Accounting Standards (IPSAS)? A measure of formal harmonization]. Contabilidad y Negocios, 12(24), 61-83. Recuperado de https://n9.cl/hjk6

Sánchez, J., \& Pincay, D. (2013). La Contabilidad Pública en América Latina y el devengo en Ecuador. [Public Accounting in Latin America and accrual in Ecuador]. Revista de Análisis Estadístico Analitika. (6) 19-32. Recuperado de https://n9.cl/o328

Velásquez-Graciano, O, \& Pérez- Morales, J. (2018). Convergencia a Normas Internacionales de Contabilidad para el Sector Público (NICSP): Comparativo de los modelos de Colombia y Chile. [Convergence to International Public Sector Accounting Standards (IPSAS): Comparison of the models of Colombia and Chile].Cuadernos de Contabilidad, 19(47), 24-59. https://dx.doi.org/10.11144/javeriana.cc18-45.cnic 